\title{
Uso de óleos essenciais no controle do ácaro Varroa destructor em Apis mellifera ${ }^{1}$
}

\author{
Gustavo Haralampidou da Costa Vieira ${ }^{2}$, Wagner da Paz Andrade ${ }^{2}$, Daniele Maria do Nascimento ${ }^{2}$
}

\begin{abstract}
Use of essential oils for controlling the

Varroa destructor acarus in Apis mellifera

The Varroa destructor (Acari: Varroidae) acarus is considered a major bee pest worldwide. The contamination risk of honey and wax, as well as the development of resistance by this pest, have led to the need of alternative ways for replacing conventional acaricides. This study aimed at evaluating the effects of different essential oils on the mortality of the Apis mellifera honey bee and its parasite, the Varroa destructor acarus. The methodology consisted in maintaining separately groups formed by honey bees and acarus, in cages with essential oils at the concentrations of $10 \mu \mathrm{L}, 50 \mu \mathrm{L}$ and $200 \mu \mathrm{L}$, being each concentration an essay. Treatments with water, anise, rosemary, cinnamon, eucalyptus, clove and mint were performed. The experiment was conducted in randomized blocks, with six treatments and four replications. Bee and acarus specimens were observed for six hours, in order to quantify the mortality rate caused by treatments. The essential oils did not affect significantly the honey bees, however, the anise, cinnamon, eucalyptus and clove oils caused a significant mortality rate for the acarus. Concerning the $10 \mu \mathrm{L}$ concentration, there was a mortality rate of $70 \%$ for anise and cinnamon, $77.5 \%$ for eucalyptus and $75 \%$ for clove. At the $50 \mu \mathrm{L}$ concentration, a rate of $75 \%$ was observed for clove and cinnamon, $90 \%$ for anise and $92.5 \%$ for eucalyptus. For the $200 \mu \mathrm{L}$ concentration, the mortality rates reached $92.5 \%$ for anise and eucalyptus, $52.5 \%$ for cinnamon and $87.5 \%$ for clove. Based on the mortality rates observed in the study, it is suggested that these substances can replace conventional acaricides.
\end{abstract}

KEY-WORDS: Honey bee; natural acaricide; alternative pest control.

\section{INTRODUÇÃO}

O ácaro Varroa destructor (Acari: Varroidae) é um ectoparasita de abelhas, que causa danos tanto às crias quanto às abelhas adultas, além de ser importante vetor de diversas doenças, como o vírus de paralisia aguda de abelhas (ABPV), o vírus de abelhas

\section{RESUMO}

O ácaro Varroa destructor (Acari: Varroidae) é considerado uma das principais pragas apícolas mundiais. O risco de contaminação da cera e do mel, assim como o desenvolvimento de resistência desta praga, têm levado à busca por alternativas de controle que substituam os acaricidas convencionais. O presente trabalho objetivou determinar os efeitos de diferentes óleos essenciais na mortalidade de abelhas Apis mellifera e do ácaro Varroa destructor, parasita destes insetos. A metodologia consistiu em manter separadamente grupos formados por abelhas e ácaros, em gaiolas com óleos essenciais nas concentrações de $10 \mu \mathrm{L}, 50 \mu \mathrm{L}$ e $200 \mu \mathrm{L}$, sendo cada concentração um ensaio. Foram realizados tratamentos com água, anis, alecrim, canela, eucalipto, cravo e menta. O delineamento experimental foi em blocos casualizados, com seis tratamentos e quatro repetições. As abelhas e ácaros foram observados por seis horas, para a quantificação da mortalidade, em função dos tratamentos utilizados. Os óleos essenciais não afetaram as abelhas de forma significativa, contudo, os óleos de anis, canela, eucalipto e cravo causaram mortalidade significativa dos ácaros. Para a concentração de $10 \mu \mathrm{L}$, observou-se taxa de mortalidade de $70 \%$ para anis e canela, $77,5 \%$ para eucalipto e $75 \%$ para cravo. Na concentração de $50 \mu \mathrm{L}$, foram observados valores de $75 \%$ para cravo e canela, $90 \%$ para anis e $92,5 \%$ para eucalipto. Já na concentração de $200 \mu \mathrm{L}$, os valores de mortalidade foram de $92,5 \%$ para anis e eucalipto, $52,5 \%$ para canela e $87,5 \%$ para cravo. Com base na taxa de mortalidade observada, sugere-se que estas substâncias sejam usadas em substituição aos acaricidas convencionais.

PALAVRAS-CHAVE: Abelha; acaricida natural; controle alternativo de pragas.

Kashmir (KBV) e o vírus que deforma a asa (DWV) (Chen et al. 2004, Tentcheva et al. 2006).

É considerado, atualmente, uma das principais pragas apícolas mundiais (Castagnino 2008), tendo se estabelecido no Brasil na década de 1970, com a importação de abelhas e rainhas do Paraguai (De Jong et al. 1982).

1. Trabalho recebido em maio/2012 e aceito para publicação em set./2012 ( $\mathrm{n}^{\circ}$ registro: PAT 18567).

2. Universidade Estadual de Mato Grosso do Sul (UEMS), Unidade Universitária de Cassilândia, Cassilândia, MS, Brasil. E-mails: gcv@uems.br, wagnerwinver@hotmail.com,daniele_ocz@hotmail.com. 
Inicialmente comum apenas em colmeias de Apis cerana (Hymenoptera: Apidae) (Gupta 1961), expandiu seus ataques à Apis mellifera (Hymenoptera: Apidae), a partir da década de 1960, provavelmente em função da transferência de quadros entre colmeias destas duas espécies (Definado 1963).

Estudos concluíram que as abelhas parasitadas por $V$. destructor apresentam redução de até $25 \%$ em seu peso, quando comparadas com abelhas normais (De Jong et al. 1982). No caso das colmeias, infestações severas podem causar sua completa destruição (Montiel \& Piola 1976).

Para minimizar os efeitos deste ácaro, vários acaricidas sintéticos foram desenvolvidos. Dentre os produtos químicos mais usados, pode-se citar o fluvalinato, a flumethrina e o ácido fórmico (Manrique 2001). O fluvalinato e a flumethrina são piretroides sintéticos. O primeiro foi, inicialmente, usado para controle de ácaros em plantas ornamentais, porém, sua eficiência permitiu o uso em colmeias. O segundo foi usado diretamente no controle de ácaros em colmeias de Apis mellifera. O ácido fórmico é um produto natural muito volátil e cáustico, que chega a eliminar $85 \%$ dos parasitas na colmeia (Manrique 2001).

Entretanto, o uso de produtos químicos, além de não ter eficácia comprovada, interfere diretamente na qualidade do mel e, consequentemente, no seu valor de mercado, visto que deixa resíduos tóxicos neste produto, tornando-o impróprio ao consumo humano. Além disto, o uso prolongado desses acaricidas favorece o desenvolvimento de resistência nos ácaros (Milani 1995).

Alguns estudos baseados no controle biológico e no uso de produtos naturais foram realizados, com o intuito de se obter uma estratégia de controle da varroatose que não ofereça risco de contaminação da cera e do mel. Lindberg et al. (2000) realizaram testes in vitro com diferentes substâncias, como o óleo de cravo da Índia, acetato de benzila e timol, dentre outros, e observaram que muitos deles têm elevada eficiência no controle do ácaro $V$. destructor e baixa toxidade às abelhas. Assis (2010) também testou a eficiência de óleos essenciais extraídos de Cinnamomum zeylanicum (Blume.), Eugenia uniflora (Berg.), Eugenia uvalha (Cambess.), Melaleuca leucadendra L., Piper marginatum (Jacq.) e Schinus terebinthifolius, no controle de ácaros, obtendo resultados satisfatórios.
Com relação aos óleos essenciais, sabe-se que estas substâncias são produzidas por plantas, sendo importante mecanismo de proteção contra o ataque de insetos, ácaros e patógenos, pois exercem, nestes organismos, efeito tóxico, interferindo nas suas funções bioquímicas e fisiológicas (Salisbury \& Ross 1992).

$\mathrm{O}$ interesse pelo uso de óleos essenciais no controle de ácaros não se deve apenas ao sucesso obtido na mortalidade destes artrópodos, mas, também, à baixa toxidade destas substâncias às abelhas e ao pouco poder residual deixado no mel e cera (Imdorf et al. 1995).

Considerando-se a importância ecológica e econômica das abelhas e os prejuízos que a apicultura sofreu nos últimos anos, em função do parasitismo ocasionado por esse ácaro, o presente estudo foi desenvolvido com o objetivo de determinar o potencial de diferentes óleos essenciais no controle de $V$. destructor, em colmeias de A. mellifera.

\section{MATERIAL E MÉTODOS}

O trabalho foi desenvolvido de setembro a novembro de 2011, no Laboratório de Apicultura da Universidade Estadual de Mato Grosso do Sul,

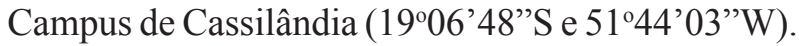

O teste de sensibilidade das abelhas aos óleos essenciais foi realizado conforme metodologia proposta por Castagnino (2008), utilizando-se grupos formados por vinte operárias, mantidos em gaiolas plásticas de $10 \mathrm{~cm}$ x $10 \mathrm{~cm}$, contendo, no seu interior, um bloco de esponja floral $\left(1,0 \mathrm{~cm}^{2}\right)$, para embebição dos óleos essenciais (Figura 1). Os óleos (fornecidos por Dierberger Óleos Essenciais S. A.) foram adicionados à esponja floral com o auxílio de uma micropipeta, sendo realizados três ensaios ( $10 \mu \mathrm{L}, 50 \mu \mathrm{L}$ e $200 \mu \mathrm{L})$, para os seguintes

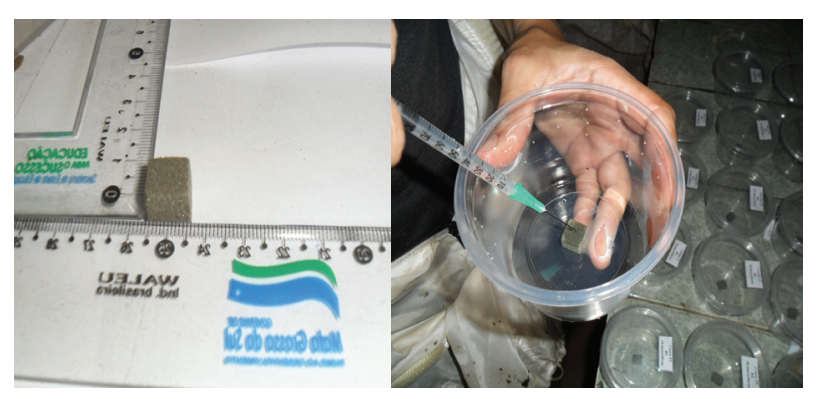

Figura 1. Esponja floral usada para a aplicação dos óleos essenciais (Cassilândia, MS, 2011). 
tratamentos: T0: água; T1: óleo de anis; T2: óleo de alecrim; T3: canela; T4: óleo de eucalipto; T5: óleo de cravo; e T6: óleo de menta. O delineamento experimental foi em blocos casualizados, com seis tratamentos e quatro repetições. As abelhas foram observadas por seis horas, sendo quantificada a taxa de sobrevivência dos indivíduos. Foram consideradas mortas as abelhas que permaneceram imóveis após trinta minutos do término da exposição à substância testada.

Os testes de eficiência dos óleos essenciais sobre $V$. destructor foram similares aos realizados para A. mellifera. Para cada tratamento, foram utilizadas sete gaiolas de $10 \mathrm{~cm} \times 10 \mathrm{~cm}$, contendo 10 ácaros e um bloco de esponja floral $\left(1,0 \mathrm{~cm}^{2}\right)$. Os ácaros foram obtidos diretamente das abelhas operárias, tomando-se o cuidado de selecionar apenas indivíduos adultos, sendo transferidos para as gaiolas com o auxílio de um pincel de cerdas macias, evitando-se o contato direto com a esponja. Mantiveram-se, para os ácaros, as mesmas dosagens e tratamentos.

Os ácaros foram observados por um período de seis horas nas placas, sendo quantificada a taxa de mortalidade em decorrência do efeito dos produtos testados. Foram considerados mortos os ácaros que permaneceram imóveis após trinta minutos do término da exposição à substância testada.

Os resultados foram submetidos à análise de variância e as médias comparadas pelo teste Tukey, a 5\%.

\section{RESULTADOS E DISCUSSÃO}

Os óleos essenciais não influenciaram na taxa de mortalidade das abelhas, em relação ao grupo controle, porém, causaram a morte dos ácaros de forma significativa, em todos os ensaios realizados (Tabelas 1 a 3). Na concentração de $10 \mu \mathrm{L}$, as taxas de sobrevivência de $A$. mellifera foram superiores a $95 \%$. Nesta concentração, a mortalidade dos ácaros variou de $30 \%$ a $77,5 \%$, sendo os maiores valores observados para os óleos de anis, canela, eucalipto e cravo (Tabela 1).

Os resultados observados para $50 \mu \mathrm{L}$ foram semelhantes aos encontrados para $10 \mu \mathrm{L}$. Nesta concentração, os óleos não causaram mortalidade de A. mellifera, porém, afetaram, de forma significativa, a mortalidade dos ácaros (Tabela 2). As taxas de sobrevivência das abelhas foram iguais ou superiores a 95\%, enquanto os ácaros apresentaram valores de mortalidade variando de $32,5 \%$ a $92,5 \%$, sendo os maiores índices obtidos para os óleos de anis, canela, eucalipto e cravo (Tabela 2).

Para a concentração de $200 \mu \mathrm{L}$, os índices de sobrevivência de $A$. mellifera ficaram próximos aos observados para as demais doses testadas, atingindo valores acima de $85 \%$, para todos os tratamentos realizados. Nesta concentração, as taxas de mortalidade do ácaro variaram de $47,5 \%$ a $92,5 \%$, sendo os maiores índices obtidos para os óleos de anis, eucalipto e cravo (Tabela 3).

Resultados semelhantes aos observados neste trabalho foram obtidos em outros estudos. Castagnino (2008) testou a eficiência de óleos essenciais de arruda, hortelã, timol e eucalipto, na mortalidade de abelhas, observando que estas substâncias não causaram a morte deste inseto.

A baixa toxidade dos óleos essenciais para abelhas também foi observada por Miresmailli et al. (2006). Segundo estes autores, alguns óleos essenciais são aplicáveis a determinados grupos de

Tabela 1. Taxa de sobrevivência de Apis mellifera e mortalidade do ácaro Varroa destructor, após seis horas de exposição a diferentes óleos essenciais, na concentração de $10 \mu \mathrm{L}$ (Cassilândia, MS, 2011).

\begin{tabular}{|c|c|c|c|c|}
\hline \multirow{3}{*}{ Óleo essencial } & \multicolumn{2}{|c|}{ Apis mellifera } & \multicolumn{2}{|c|}{ Varroa destructor } \\
\hline & \multicolumn{2}{|c|}{ Sobrevivência } & \multicolumn{2}{|c|}{ - Mortalidade } \\
\hline & Média & $\%$ & Média & $\%$ \\
\hline Controle (água) & $18,75 \pm 0,96 \mathrm{a}$ & 93,75 & $0,00 \pm 0,00 \mathrm{a}$ & 0,00 \\
\hline Anis & $19,75 \pm 0,50 \mathrm{a}$ & 98,75 & $7,00 \pm 3,82 \mathrm{bc}$ & 70,00 \\
\hline Alecrim & $19,75 \pm 0,50 \mathrm{a}$ & 98,75 & $5,25 \pm 0,95 \mathrm{bc}$ & 52,50 \\
\hline Canela & $19,25 \pm 0,96 \mathrm{a}$ & 96,25 & $7,00 \pm 0,81 \mathrm{bc}$ & 70,00 \\
\hline Eucalipto & $19,50 \pm 0,58 \mathrm{a}$ & 97,50 & $7,75 \pm 1,50 \mathrm{c}$ & 77,50 \\
\hline Cravo & $19,50 \pm 0,58 \mathrm{a}$ & 97,50 & $7,50 \pm 0,57 \mathrm{c}$ & 75,00 \\
\hline Menta & $19,75 \pm 0,50 \mathrm{a}$ & 98,75 & $3,00 \pm 2,30 \mathrm{ab}$ & 30,00 \\
\hline D.M.S. & 1,56 & & 4,27 & \\
\hline
\end{tabular}


Tabela 2. Taxa de sobrevivência de Apis mellifera e mortalidade do ácaro Varroa destructor, após seis horas de exposição a diferentes óleos essenciais, na concentração de $50 \mu \mathrm{L}$ (Cassilândia, MS, 2011).

\begin{tabular}{|c|c|c|c|c|}
\hline \multirow{3}{*}{ Óleo essencial } & \multicolumn{2}{|c|}{ Apis mellifera } & \multicolumn{2}{|c|}{ Varroa destructor } \\
\hline & \multicolumn{2}{|c|}{ Sobrevivência } & \multicolumn{2}{|c|}{ - Mortalidade - } \\
\hline & Média & $\%$ & Média & $\%$ \\
\hline Controle (água) & $18,75 \pm 0,96 \mathrm{a}$ & 93,75 & $0,25 \pm 0,50 \mathrm{a}$ & 2,50 \\
\hline Anis & $19,50 \pm 0,58 \mathrm{a}$ & 97,50 & $9,00 \pm 0,82 \mathrm{de}$ & 90,00 \\
\hline Alecrim & $19,25 \pm 0,50 \mathrm{a}$ & 96,25 & $6,25 \pm 0,50 \mathrm{c}$ & 62,50 \\
\hline Canela & $19,00 \pm 0,82 \mathrm{a}$ & 95,00 & $7,50 \pm 1,00 \mathrm{~cd}$ & 75,00 \\
\hline Eucalipto & $19,50 \pm 0,58 \mathrm{a}$ & 97,50 & $9,25 \pm 0,96 \mathrm{e}$ & 92,50 \\
\hline Cravo & $19,00 \pm 1,41 \mathrm{a}$ & 95,00 & $7,50 \pm 0,58 \mathrm{~cd}$ & 75,00 \\
\hline Menta & $19,25 \pm 0,50 \mathrm{a}$ & 96,25 & $3,25 \pm 0,50 \mathrm{~b}$ & 32,50 \\
\hline D.M.S. & 1,89 & & 1,66 & \\
\hline
\end{tabular}

Valores seguidos de letras iguais, na mesma coluna, não diferem estatisticamente entre si, a 5\%.

Tabela 3. Taxa de sobrevivência de Apis mellifera e mortalidade do ácaro Varroa destructor, após seis horas de exposição a diferentes óleos essenciais, na concentração de $200 \mu \mathrm{L}$ (Cassilândia, MS, 2011).

\begin{tabular}{|c|c|c|c|c|}
\hline \multirow{3}{*}{ Óleo essencial } & \multicolumn{2}{|c|}{ Apis mellifera } & \multicolumn{2}{|c|}{ Varroa destructor } \\
\hline & \multicolumn{2}{|c|}{ - Sobrevivência } & \multicolumn{2}{|c|}{ - Mortalidade } \\
\hline & Média & $\%$ & Média & $\%$ \\
\hline Controle (água) & $18,50 \pm 1,29 \mathrm{a}$ & 92,50 & $0,25 \pm 0,50 \mathrm{a}$ & 2,50 \\
\hline Anis & $19,25 \pm 0,50 \mathrm{a}$ & 96,25 & $9,25 \pm 0,96 \mathrm{~d}$ & 92,50 \\
\hline Alecrim & $19,25 \pm 0,50 \mathrm{a}$ & 96,25 & $7,75 \pm 0,96 \mathrm{~cd}$ & 77,50 \\
\hline Canela & $19,00 \pm 0,82 \mathrm{a}$ & 95,00 & $5,25 \pm 2,06 \mathrm{bc}$ & 52,50 \\
\hline Eucalipto & $17,25 \pm 0,50 \mathrm{a}$ & 86,25 & $9,25 \pm 0,50 \mathrm{~d}$ & 92,50 \\
\hline Cravo & $17,25 \pm 0,96 \mathrm{a}$ & 86,25 & $8,75 \pm 1,26 \mathrm{~d}$ & 87,50 \\
\hline Menta & $18,75 \pm 1,50 \mathrm{a}$ & 93,75 & $4,75 \pm 0,96 \mathrm{~b}$ & 47,50 \\
\hline D.M.S. & 2,17 & & 2,62 & \\
\hline
\end{tabular}

Valores seguidos de letras iguais, na mesma coluna, não diferem estatisticamente entre si, a 5\%.

organismos, podendo, assim, ser usados em conjunto com o controle biológico. Esta condição permite o uso destas substâncias no controle de ácaros em colmeias de $A$. mellifera.

Um dos fatores que explica a alta taxa de mortalidade apresentada por esse grupo de óleos seria a presença de substâncias secundárias, como a citronela, cuja ação acaricida e inseticida é bem conhecida (Prates et al. 1998).

Por outro lado, autores como Tapondjou et al. (2002), Singh et al. (2003) e Aslan et al. (2004a,b) sugerem, em seus trabalhos, que, talvez, a toxicidade observada nos óleos essenciais esteja relacionada aos seus componentes principais.

A atividade dos óleos essenciais sobre o ácaro $V$. destructor pode ser influenciada não apenas pela composição química de cada óleo e dose (Kordali et al. 2006), mas, também, pela susceptibilidade da espécie estudada. Assim, os maiores valores obtidos para concentração/mortalidade indicam alto grau de sensibilidade e correlação entre dose do óleo essencial e mortalidade.
Dentre os óleos testados, o eucalipto proporcionou a maior taxa de mortalidade de ácaros e, com relação às abelhas, os resultados obtidos para a taxa de mortalidade com eucalipto corroboram os observados por Castagnino (2008), que submeteu abelhas $A$. mellifera a diferentes concentrações de óleos essenciais e não encontrou diferença significativa na taxa de mortalidade dos insetos, em relação ao grupo controle.

Quanto ao mecanismo de ação do óleo sobre os ácaros, acredita-se que, embora esta ação seja pouco conhecida (Kim et al. 2004), o seu efeito rápido seria indicativo de uma ação neurotóxica (Isman 2006). Por outro lado, Moraes \& Flechtmann (2008) afirmaram que os óleos essenciais apresentam efeito tóxico aos ácaros, pois penetram no corpo destes artrópodos por meio da cutícula, que corresponde à sua única superfície respiratória.

O uso de acaricidas a base de óleos essenciais é promissor para a apicultura, visto que os tratamentos com acaricidas convencionais a base de organofos- 
forados, clorados e piretroides, além de favorecer o desenvolvimento de resistência nas populações dos ácaros (Lodesani 2004), pode causar, ainda, a contaminação dos produtos das abelhas, como o mel e a cera (Bogdanov 2006).

Outro aspecto positivo, com relação ao uso dos óleos essenciais, é que estes compostos são mais facilmente registrados, em relação aos inseticidas sintéticos (Assis 2010). Outras características, como a rápida degradação no ambiente e a aparente segurança para mamíferos, aumenta o interesse no uso destas substâncias. Porém, estudos sobre efeitos toxicológicos, alteração na qualidade dos produtos tratados, relação custo/benefício do uso e segurança no uso destes produtos ainda são necessários (Cloyd et al. 2009).

Parte dos óleos essenciais discutidos neste trabalho constituem possíveis alternativas de substituição aos acaricidas convencionais sintéticos e podem compor a nova geração de compostos ecologicamente adequados, capazes de garantir ao apicultor o manejo sustentável de suas colmeias. Sabe-se, por meio de estudos, que o apicultor não deve utilizar produtos sintéticos para o controle de quaisquer doenças, sob o risco de contaminar o mel, a cera ou, ainda, favorecer o desenvolvimento da resistência dos parasitas (Boot et al. 1995).

\section{CONCLUSÕES}

1. Os óleos essenciais de anis, alecrim, canela, eucalipto, cravo e menta não ocasionaram a morte de abelhas $A$. mellifera, de forma significativamente superior ao controle.

2. Os óleos essenciais de anis, eucalipto e cravo foram eficientes no controle de ácaros $V$. destructor, tendo apresentado elevadas taxas de mortalidade, para as concentrações testadas. Sugere-se, com base nos resultados, o uso destas substâncias, em substituição aos acaricidas convencionais.

\section{REFERÊNCIAS}

ASLAN, I. et al. Toxicity of essential oil vapours to two greenhouse pests, Tetranychus urticae Koch and Bemisia tabaci Genn. Industrial Crops and Products, Leiden, v. 19, n. 2, p. 167-173, 2004a.

ASLAN, I. et al. Toxicity of essential oil vapours obtained from Pistacia spp. to the granary weevil, Sitophilus granarius (L.) (Coleoptera: Curculionidae). Journal of
Plants Diseases Protection, Stuttgart, v. 111, n. 4, p. 400407, 2004b.

ASSIS, C. P. O. Toxidade de óleos essenciais sobre Tyrophagus putrescentiae (SCHRANK) e Suidasia pontifica OUDEMANS (Acari: Astigmata). 2010. 32 f. Dissertação (Mestrado em Entomologia Agrícola) Universidade Federal Rural de Pernambuco, Recife, 2010.

BOGDANOV, S. Contaminants of bee products. Apidologie, Les Ulis, v. 37, n. 1, p. 1-18, 2006.

BOOT, W. J.; VAN BAALEN, M.; SABELIS, M. W. Why do Varroa mites invade worker brood cells of the honey bee despite lower reproductive success. Behaviour Ecology Sociobiology, Berlin, v. 36, n. 4, p. 283-289, 1995.

CASTAGNINO, G. L. B. Produtos naturais no controle do ácaro Varroa destructor em abelhas Apis mellifera L. (africanizadas). 2008. 53 f. Tese (Doutorado em Zootecnia) - Universidade Estadual Paulista, Botucatu, 2008.

CHEN, Y. et al. Transmission of Kashmir bee virus by the ectoparasitic mite Varroa destructor. Apidologie, Les Ulis, v. 35, n. 4, p. 441-448, 2004.

CLOYD, R. A. et al. Effect of pesticides on adult rove beetle Atheta coriaria (Coleoptera: Staphylinidae) survival in growing medium. Journal of Economic Entomology, Lanham, v. 102, n. 5, p. 1750-1758, 2009.

DE JONG, D.; MORSE, R. A.; EICKWORT, G. C. Mite pests of honey bees. Annual Review of Entomology, Stanford, v. 27, n. 1, p. 229-52, 1982.

DELFINADO, M. D. Mites of the honeybees in SouthEast Asia. Journal of Apicultural Research, Cardiff, v. 2, n. 1, p. 113-14, 1963.

GUPTA, G. A. Varroa jacobsoni: a mite pest of Apis indica. Bee World, Cardiff, v. 48, n. 1, p. 17-18, 1961.

IMDORF, A. et al. Apilife Var: a new varroacide with thymol as the main ingredient. Bee World, Cardiff, v. 76, n. 1, p. 77-83, 1995.

ISMAN, M. B. The role of botanical insecticides, deterrents and repellents in modern agriculture and an increasingly regulated world. Annual Review Entomology, Stanford, v. 51, n. 1, p. 45-66, 2006.

KIM, H. K.; KIM, J. R.; AHN, Y. J. Acaricidal activity of cinnamaldehyde and its congeners against Tyrophagus putrescentiae (Acari: Acaridae). Journal of Stored Products Research, Leiden, v. 40, n. 1, p. 55-63, 2004.

KORDALI, S. et al. Toxicity of essential oils isolated from three Artemisia species and some of their major components to granary weevil, Sitophilus granarius (L.) (Coleoptera: Curculionidae). Industrial Crops and Products, Leiden, v. 23, n. 2, p. 162-170, 2006. 
LINDBERG, C. M.; MELATHOPOUlOS, A. P.; WINSTON, M. L. Laboratory evaluation of miticides to control Varroa jacobsoni (Acari: Varroidae), a honey bee (Hymenoptera: Apidae) parasite. Journal of Economic Entomology, Lanham, v. 93, n. 2, p.189-198, 2000.

LODESANI, M. Control strategies against Varroa mites. Parassitologia, Roma, v. 46, n. 1-2, p. 277-279, 2004.

MANRIQUE, A. J. Controle da Varroa e seu efeito sobre a produção de mel Apis mellifera na Venezuela. Interciência, Rio de Janeiro, v. 26, n. 1, p. 25-28, 2001.

MILANI, N. The resistance of Varroa jacobsoni Oud. to pyrethroids: a laboratory assay. Apidologie, Les Ulis, v. 26, n. 5, p. 415-429, 1995.

MIRESMAILLI, S.; BRADBURY, R.; ISMAN, M. B. Comparative toxicity of Rosmarinus officinalis L. essential oil and blends of its major constituents against Tetranychus urticae Koch (Acari: Tetranychidae) on two different host plants. Pest Management Science, Oxford, v. 62 , n. 4, p. 366-371, 2006.

MONTIEL, J. C.; PIOLA, G. A. A new enemy of bees. In: MONTIEL, J. C.; PIOLA, G. A. Varroasis, a honeybee disease. Bucharest: Apimondia, 1976. p. 36-37.
MORAES, G. J.; FLECHTMANN, C. H. W. Manual de acarologia: acarologia básica e ácaros de plantas cultivadas no Brasil. Ribeirão Preto: Holos, 2008.

PRATES, H. T. et al. Insecticidal activity of monoterpenes against Rhyzopertha dominica (F.) and Tribolium castaneum (Herbst). Journal of Stored Products Research, Leiden, v. 34, n. 4, p. 243-249, 1998.

SALISBURY, F. B.; ROSS, C. W. Plant physiology. Belmont: Wadsworth, 1992.

SINGH, G. et al. Studies on essential oils: chemical and biocidal investigation on Tagetes erecta leaf volatile oil. Flavour and Fragrance Journal, Hoboken, v. 18, n. 1, p. 62-65, 2003.

TAPONDJOU, L. A. et al. Efficacy of powder and essential oil from Chenopodium ambrosioides leaves as post-harvest grain protectants against six-stored product beetles. Journal of Stored Products Research, Leiden, v. 38, n. 4, p. 395-402, 2002.

TENTCHEVA, D. et al. Comparative analysis of deformed wing virus (DWV) RNA in Apis mellifera and Varroa destructor. Apidologie, Les Ulis, v. 37, n. 1, p. 41-50, 2006. 